\title{
Diglossia in the Arab World
}

\section{-Educational Implications and Future Perspectives}

\author{
Christopher Horn \\ University of New England, Armidale, Australia \\ Email: nashledanou@gmail.com
}

Received 20 January 2015; accepted 14 February 2015; published 17 February 2015

Copyright (C) 2015 by author and Scientific Research Publishing Inc.

This work is licensed under the Creative Commons Attribution International License (CC BY). http://creativecommons.org/licenses/by/4.0/

\section{(c) (i) Open Access}

\begin{abstract}
This essay will offer an introduction to the long-debated issue of diglossia in the Arabic-speaking world, together with an overview of some of the effects it brings about within the Arab society against the background of the governing Islamic creed. After a definition of the issue, backed by the most relevant, related academic literature, a brief overview will be offered of the social setting in which this situation has perpetuated itself to this day. The author will then proceed to assess the impact of diglossia on Arab youth, nowadays, with an eye on educational concerns, and will conclude with a tentative speculation on the future of Arabic as a language, in hopes to inspire further academic endeavor.
\end{abstract}

\section{Keywords}

Arabic, Lingua Franca, Diglossia, Vernacular, Formal, Corpus Linguistics, Education, Technology

\section{Introduction}

Throughout the Arab world, extending from Morocco to Iraq and encompassing the Gulf Countries and the Levant, for centuries one formal language has been taught systematically in all schools and universities and used regularly by TV, magazines, newspapers and in literature. This language is commonly referred to-chiefly by Western scholars-as Modern Standard Arabic (hereinafter, MSA). Its lexicon and grammatical structure can be regarded as an adaptation/modernization of the language used in the Holy Koran (Zughoul 1980; Mendenhall 2006), in which all these nations consider the book for all matters concerning religion, law, customs and morals-in a word, life. It is a historical fact that all the Arab peoples were culturally united by the preaching of the Prophet Mohammed; the role and importance of Islam in the whole area can hardly be overestimated in the analysis of the social phenomenon of language.

Despite the existence of such a lingua franca (MSA), which—at least theoretically—every educated Arab is 
capable of speaking and understanding, the language that is actually used in all informal situations is, to varying extents, dissimilar from MSA and depends on the geographical provenance of the speakers. Different peoples in different countries use their own distinctive vernaculars (henceforth collectively referred to as Dialectal Arabic, or DA), which are grammatically and lexically less complex, have an exclusively oral form and are hardly ever written, and which enjoy fluctuating degrees of intelligibility with both MSA and one another: while natives of adjacent areas more easily understand each other's respective patois, the Moroccan dialect would be as good as unintelligible to natives of the Gulf (Kaye 2001)—in the same fashion as the Portuguese language is extremely difficult for Romanian-speaking people to understand, even though both originate from the same ancestor (Latin).

It should be noted that "formal" and "informal" are provisional terms for denoting what are actually indiscrete circumstances in which language is produced. As Albirini (2011) aptly observes, what happens in all these countries is a phenomenon known as code-switching: while people will use DA in most situations, they occasionally shift to MSA whenever they intend to attach formality or seriousness (whether real or ironic) to their verbal utterances, and conversely, they revert to DA when they want to make them sound less "imperative", i.e. to adopt a politeness strategy; these shifts take place pervasively, even in one single segment of speech (as formulaic expressions, for example).

This situation is called diglossia. This term, initially a French word coined by Marçais (1930), has been calqued and given academic attention by the American linguist C.A. Ferguson, who in his 1959 eponymously-titled seminal article, "Diglossia", considered the characteristics of bidialectal (as opposed to bilingual) situations that exist in linguistic communities where two varieties—a vernacular, ill-defined or "low" one, and a standard, defined or "high" one-are used by natives in complementary distribution, according to the contingent situation (Ferguson 1959; cf. also Hawkins 1983).

On the trail of Ferguson's article, several other scholars have been dealing with different aspects of the same issue. One of the earliest critics, Kaye, reversed Ferguson's construal of the state of definition for the two Arabic varieties by demonstrating that the much-idealized MSA, in actual fact, is far from being stable as it is subject to both phonological and syntactical variation depending on the local DA, which then ends up being the better defined idiom (Kaye 1972).

\section{Social Background}

Arabs' attitudes towards the state of their language adhere to a generally unconcerned pattern: the only language whose existence is socially acknowledged is the prestigious MSA, whereas DA has historically never been given much importance or recognition, since it has always been considered a bastardization of the original, "pure" language. Natives who are asked if they speak Arabic regularly understand the question as to whether they master the classical register, and will regard their dialectal forms as unworthy of consideration (cf. Herbolich 1979 and also Albirini 2011).

However, for daily, practical matters, the use of MSA is socially regarded as incongruous, almost vilifying in respect to the "high" functions the MSA is supposed to accomplish: as Kaye (2001) observes, "speaking MSA to one's maid at home or bargaining over the price of an item in a crowded market in MSA would be absurd, even ludicrous". As a tentative parallel with the English language, we could say that it would be tantamount to speaking to a friend using, instead of the normal "why did you speak", a literary archaic sentence like "wherefore spake thee": at best, it would be perceived as an attempt at irony.

In this light we can better view why the diglossic situation survives in the Arab world despite the pan-Arabistic attempts to deploy MSA as the one and only form of all the twenty-two national territories in question. One viewpoint is offered by Zughoul (1980), who imputes the gap between DA and MSA to an endemic situation of illiteracy and poverty in the Arab world, supposedly caused by "Turkish domination" and "Western colonial exploitation"; in a less politically-slanted and more realistic fashion, Abu-Rabia (2000) notes that the existence of a lower code is perpetuated in a vicious circle by both parents and educators, among whom the long-ingrained, popular belief persists that children would be too challenged to grasp the structural complexity of MSA, and who are therefore more inclined to resort to DA in their everyday interactions with young learners.

\section{Present Issues}

The diglossic situation is inevitably accompanied by sociological and sociopolitical aspects that revolve about the above-mentioned feelings of pan-Arabism instilled by a common religion and culture. In this regard, the 
study conducted with a relatively small number of participants by Zughoul (1980) is particularly significant as it reports that a general idea appears to be shared by most if not all Arabs: no vernacular should be ever adopted as official language by any Arab country, as this would entail "undesirable" consequences:

- MSA would eventually disappear to be replaced by the local vernaculars, in the same fashion as Latin died with the advent of Romance languages, so the "unifying force" guaranteed by the lingua franca would no longer exist;

- This scenario runs counter the principles of Islam (which exalts Arabic as the "perfect" language) because it would lead to the eventual "unintelligibility of the Koran" and the vanishing of "Arab traditions and culture", a fact which could be then exploited by "Western colonialists" to dominate the Arab peoples;

- The local idioms are not sophisticated enough to provide adequate means of communication, anyway.

While the first two points seem to be rooted in religious/ideological grounds, the last one is somewhat substantiated by the fact that DA has never enjoyed a regulated written form. This very fact is of great importance when we consider the process of reading acquisition.

Arab children spend the first years of their lives in families that—as mentioned above-consider it outlandish to speak to them in MSA. Their first approach to reading and writing, however, confronts them with considerable difficulties, in that they suddenly have to cope with a language that is vastly (syntactically, lexically, grammatically and phonologically) different from theirs, and with which they have little or no acquaintance (AbuRabia 2000). Unlike children from England, for example, who can expect to hear from their parents the very same sentences they read in an English book or newspaper, Arab children start their schooling with the distinct impression that setting about reading is an academically onerous task per se disconnected from the "verbal" reality of their world.

The simplest illustration for this can be provided by Table 1 (adapted from Kaye, 2001), where a question as common as "what do you want" in MSA is contrasted with its version in four different vernaculars: arguably, the difference can be as stark as that between English and the Dutch "wat wil jij" or the Spanish "que quieres", which definitely suggests that learning MSA for young learners often configures as second language acquisition proper.

In several studies conducted over the past decade, Saeigh-Haddad has investigated this specific phenomenon extensively, focusing on those phonetic and phonological differences between DA and MSA that appear to impact the learners' proficiency, on the assumption that "an awareness of the phonological structure of words is a prerequisite to the acquisition of word reading” (Saeigh-Haddad 2003, emphasis mine). Imparting the phonological structure of MSA to kids who are not acquainted with it, we could exemplify, is like expecting English children to learn to read, pronounce and eventually use in writing the German velar fricative [x], or the French uvular trill $[\mathrm{R}]$, or "exotic" consonant clusters like the Swahili word-initial [mb], without having ever heard the actual sound (cf. also Saeigh-Haddad 2005).

One notable result of this is that even MSA ends up being pronounced differently according to the geographical region, as noted by Kaye (1972); but more importantly, young learners' literary acquisition is negatively affected and their motivation for further study, in general, is endangered, as they cannot perceive that the language in which they have to function in school is really "theirs" and may easily conclude that the entire educational process is alien to ordinary life (Saeigh-Haddad 2003 and Dadi, 2011). Such a mindset, for the development of any society, is inauspicious.

\section{Future Perspectives}

The educational scenario, nowadays, presents several nations that have tried to overhaul their educational system,

Table 1. "What do you want?".

\begin{tabular}{ccc}
\hline Language & Pronunciation (IPA) & Closest Anglophonic rendition \\
\hline MSA: ماذا تريد & [ma:ða tori:d] & /mother to read/ \\
Lebanese & [ju badak] & /shoe budduck/ \\
Sudanese & [da:yir finu] & /da year sheenoo/ \\
Egyptian & [ Ga:wiz eh] & /aweezeh/ \\
Yemeni & {$\left[\right.$ [i: $\left.: \int \mathrm{ta} \int \mathrm{ti}\right]$} & /eesh tush tea/ \\
\hline
\end{tabular}


at least at tertiary level, by instituting universities in which the medium of instruction is a foreign language: in most cases, especially the petroleum-rich Gulf countries, English (though French is still important in parts of the Maghreb and the Levant). Students are still supposed to master the Arabic language, but except for those who plan to obtain a specific degree in Islamic studies, they generally do not have to write any of their assignments in MSA. Even formal email communication within or across departments tends to take place in English.

One of the consequences of this is that MSA, influenced by foreign lexicon, structure and-as mentioned above - phonology, has evolved into a form that is usually referred to as Formal Colloquial Arabic (FCA, sometimes ECA for "Educated...”). The typological verb-subject-object (VSO) structure has been almost entirely abandoned and replaced by SVO; several technology-related neologisms have barged into the language and some particularly challenging phonemes of MSA are nowadays perceived as "retro" and replaced by simpler ones.FCA is the lingo used by educated businesspeople or travellers who wish to communicate in a less idiomatic form than their own mother tongue with all the other fellow Arabs across the region (cf. Zughoul 1980; Ryding 1991; Saiegh-Haddad 2007 and 2010).

Some of the latest factors that influence the way people relate to language production involve modern technology and the new means of communication and socialization. Two of these deserve special mention: mobile phones and social networking websites, like Facebook and Twitter. Through these, young Arabs in recent years have been exchanging personal messages worded exclusively in their local dialects. What is particularly noteworthy is that the Arabic script is never used for these forms of interaction; instead, people use combinations of numbers and Roman letters to type lexemes that bear very little resemblance to the officially-endorsed way of transliterating Arabic names or road signs: viz., Common Latinized Arabic is giving way to ASCII-ized Arabic (cf. Palfreyman \& Al-Khalil, 2003, and Al-Tamimi \& Gorgis, 2007).

This trend, which is laden with potential consequences, can be imputed to two main facts: on the one hand,the Arabic alphabet is still perceived as a distinctive mark of MSA, which still stands as a symbol of "higher" functions than teenage chatty fun; on the other, the romanization of dialectal (in-group) words can ensure and reinforce a coded secrecy in the correspondence with fellow students or friends, thereby safeguarding them from the inquisitive eyes of adult authorities. As some Emirati students put it, ASCII-ized vernacular Arabic has quickly become "a funky language for teenz to use" (Palfreyman \& Al-Khalil, 2003).

Zughoul (1980) observes that the state of lexicography is one of the aspects of Arabic Linguistics in most need of improving. Should some corpus linguistics be compiled on the basis of the countless messages exchanged among the youngest generations of Arabs through phones or Internet, for each nation it would be possible to compile a dictionary and sketch out a tentative grammar of the local dialect, which could one day become the national language.

\section{Conclusion}

Thirty-eight years ago, in the Introduction to his celebrated Arabic-English Dictionary, Wehr (1976) wrote that "there is no reason to anticipate that the written [Arabic] language will anywhere be replaced by a local dialect and forced out of practical use". Since then, owing to a larger distribution of wealth and the progress of technology, the societal forces throughout the Arab world have greatly changed; still, religion is unquestionably the most tenacious, amalgamating energy in a set of very diverse peoples, and Islam's language is MSA. Its complete disappearance cannot be too imminent. Ferguson (1959) noted that in another diglossic community, Greece, the appearance of a translation of the New Testament into the "low" version of the language (dhimotiki) in 1903 was the "occasion for serious rioting". One can only dread what a similar foray onto the Holy Koran would entail in the Arab world, nowadays.

Having said this, several clues lead to presume that the local Arabic vernaculars might eventually develop into full-fledged languages. If "a dialect is a language with [...] a navy” (M. Weinreich, quoted in Kaye, 2001), all it takes for its deployment is slipping the metaphorical anchor represented by the all-encompassing religious matters. The prospective developments could mirror what happened in Europe during the Renaissance, when Italian, French and Spanish, dialects that had existed for several centuries in the shade of Latin, eventually ousted from power the language of the Roman Church and rose to official language status. This took place in Europe around the $16^{\text {th }}$ century of the Gregorian calendar. Now we are in the $15^{\text {th }}$ century of the Islamic calendar: if the oftsuggested parallel stands, something might start to happen soon. 


\section{References}

Abu-Rabia, S. (2000). Effects of Exposure to Literary Arabic on Reading Comprehension in a Diglossic Situation. Reading and Writing: An Interdisciplinary Journal, 13, 147-157.

Albirini, A. (2011). The Sociolinguistic Functions of Codeswitching between Standard Arabic and Dialectal Arabic. Language in Society, 40, 537-562. http://dx.doi.org/10.1017/S0047404511000674

Al-Tamimi, Y., \& Gorgis, D. (2007). Romanized Jordanian Arabic Messages. The International Journal of Language Society and Culture, 21.

Dadi, S. (2011). Factors Impacting Omani Students’ Motivation. Unpublished PhD Dissertation, De Montfort University, Leicester.

Ferguson, C. A. (1959). Diglossia. Word, 15, 325-340.

Hawkins, P. (1983). Diglossia Revisited. Language Sciences, 5, 1-20. http://dx.doi.org/10.1016/S0388-0001(83)80010-2

Herbolich, J. B. (1979). Attitudes of Egyptians toward Various Arabic Vernaculars. Lingua, 47, 301-321. http://dx.doi.org/10.1016/0024-3841(79)90077-9

Kaye, A. S. (1972). Remarks on Diglossia in Arabic: Well-Defined vs. Ill-Defined. Linguistics, 81, 32-48.

Kaye, A. S. (2001). Diglossia: The State of the Art. International Journal of the Sociology of Language, 152, 117-129.

Marçais, W. (1930). La diglossie arabe. L'Enseignement Public, 97, 401-409.

Mendenhall, G. E. (2006). Arabic in Semitic Language History. Journal of the American Oriental Society, 126, 17-26.

Palfreyman, D., \& Al-Khalil, M. (2003). “A Funky Language for Teenzz to Use”: Representing Gulf Arabic in Instant Messaging. Journal of Computer-Mediated Communication, 9, 23-44.

Ryding, K. C. (1991). Proficiency Despite Diglossia: A New Approach for Arabic. The Modern Language Journal, 75, 212218. http://dx.doi.org/10.1111/j.1540-4781.1991.tb05352.x

Saiegh-Haddad, E. (2003). Linguistic Distance and Initial Reading Acquisition: The Case of Arabic Diglossia. Applied Psycholinguistics, 24, 431-451.

Saiegh-Haddad, E. (2005). Correlates of Reading Fluency in Arabic: Diglossic and Orthographic Factors. Reading and Writing, 18, 559-582. http://dx.doi.org/10.1007/s11145-005-3180-4

Saiegh-Haddad, E. (2007). Linguistic Constraints on Children's Ability to Isolate Phonemes in Arabic. Applied Psycholinguistics, 28, 607-625. http://dx.doi.org/10.1017/S0142716407070336

Saiegh-Haddad, E. (2010). The Linguistic Affiliation Constraint and Phoneme Recognition in Diglossic Arabic. Journal of Child Language, 38, 297-315. http://dx.doi.org/10.1017/S0305000909990365

Wehr, H. (1976). Introduction. In H. Wehr, \& J. M. Cowan (Eds.), Arabic-English Dictionary (pp. vii-xv). Ithaca, N.Y.: Spoken Language Services.

Zughoul, M. R. (1980). Diglossia in Arabic: Investigating Solutions. Anthropological Linguistics, 22, 201-217. 
Scientific Research Publishing (SCIRP) is one of the largest Open Access journal publishers. It is currently publishing more than 200 open access, online, peer-reviewed journals covering a wide range of academic disciplines. SCIRP serves the worldwide academic communities and contributes to the progress and application of science with its publication.

Other selected journals from SCIRP are listed as below. Submit your manuscript to us via either submit@scirp.org or Online Submission Portal.
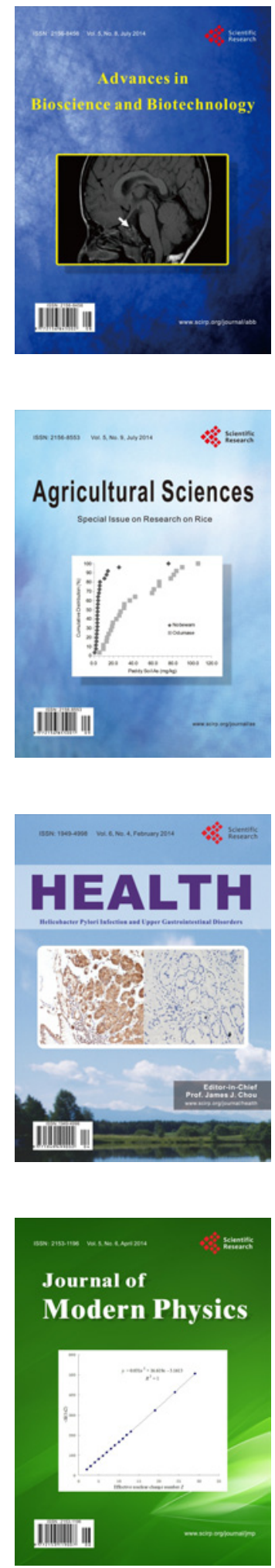
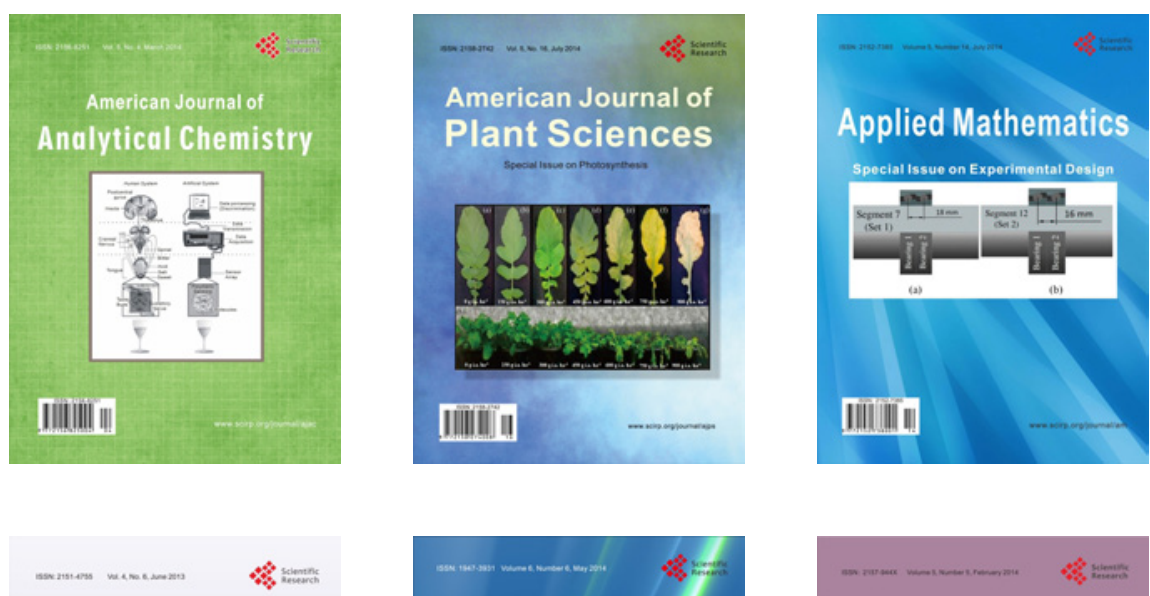

Creative Education
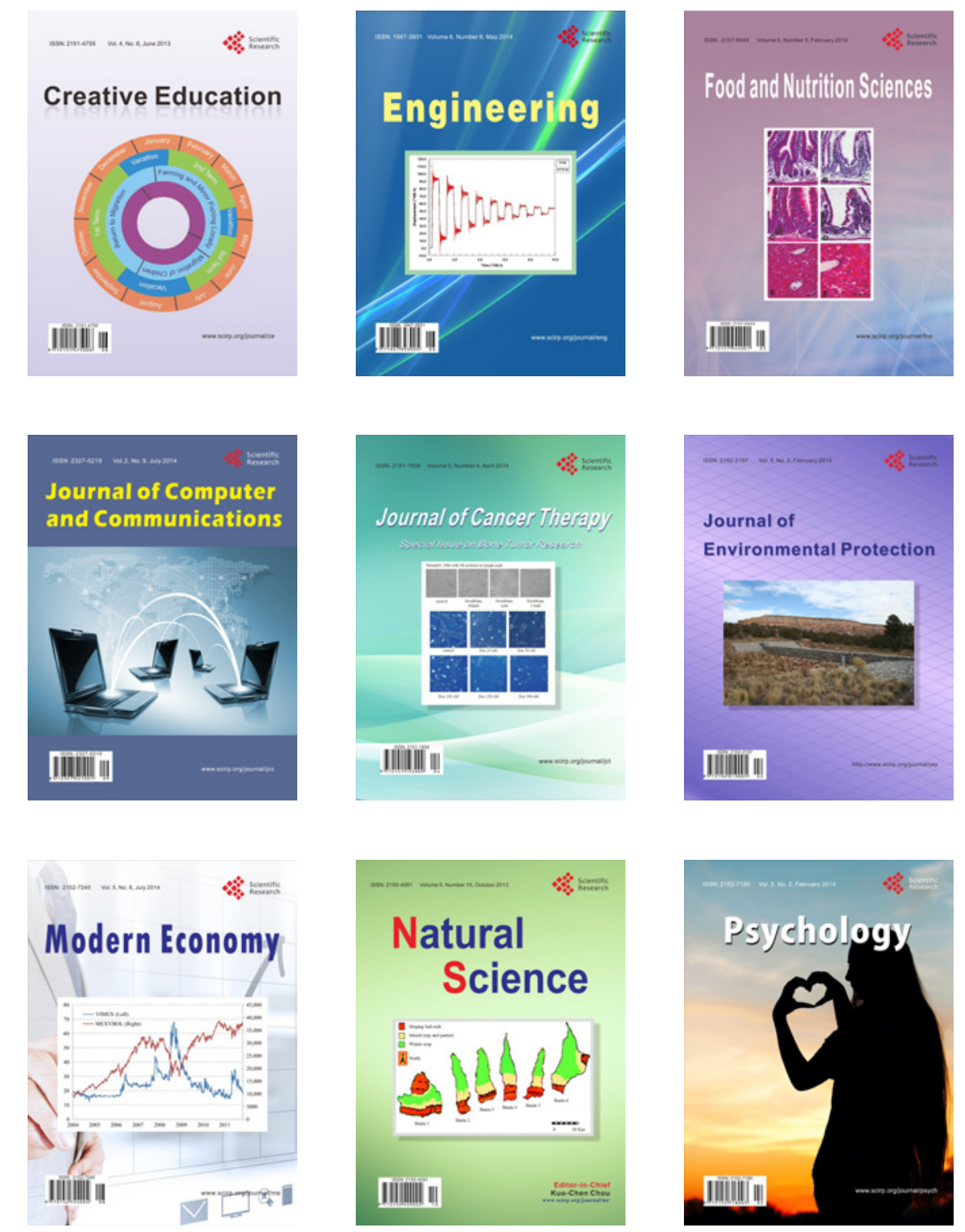